UNIVERSIDADE DE SÃO PAULO

FACULDADE DE FILOSOFIA, LETRAS E CIÊNCIAS HUMANAS

DEPARTAMENTO DE SOCIOLOGIA

PROGRAMA DE PÓS-GRADUAÇÃO EM SOCIOLOGIA

KLEBER TANDELLO PEREIRA

Florian W. Znaniecki e Henri Poincaré:

Uma Proposta de Reconstrução Metodológica

São Paulo

2014 
UNIVERSIDADE DE SÃO PAULO

FACULDADE DE FILOSOFIA, LETRAS E CIÊNCIAS HUMANAS

DEPARTAMENTO DE SOCIOLOGIA

PROGRAMA DE PÓS-GRADUAÇÃO EM SOCIOLOGIA

KLEBER TANDELLO PEREIRA

\section{Florian W. Znaniecki e Henri Poincaré: \\ Uma Proposta de Reconstrução Metodológica}

Dissertação apresentada ao Programa de Pós-Graduação em Sociologia da Faculdade de Filosofia, Letras e Ciências Humanas da Universidade de São Paulo, para a obtenção do título de Mestre em Sociologia.

Orientador: Prof. Dr. José Jeremias de Oliveira Filho

São Paulo

2014 
Dedico este trabalho a Gabriel Tandello, cuja presença amiga permanece como fonte de alegria, estímulo e perene convite para o trabalho no bem. 


\section{AGRADECIMENTOS}

Agradeço à minha esposa, Ana Mara, pela dedicação e carinho, aos meus pais e ao meu irmão, pelo suporte incondicional, à Martyna, pelo valiosíssimo suporte de pesquisa, ao Professor Mário Eufrásio, pela amizade e dedicação característica de um educador vocacionado, ao Professor José Jeremias pela gentileza e pelo amparo, ao José pela presença amiga, à equipe do Professor Langerton, cujo amparo foi fator fundamental para a execução desse trabalho, e ao CNPq, pelo auxílio financeiro. 
"Hoje, o homem de ciência se vê verdadeiramente diante de um destino trágico. Quer e deseja a verdade e a profunda independência. Mas, por esses esforços quase sobre-humanos, produziu exatamente os meios que o reduzem exteriormente à escravidão e que irão aniquilá-lo em seu íntimo. Deveria autorizar aos representantes do poder político que lhe pusessem uma mordaça. E como soldado, vê-se obrigado a sacrificar a vida de outrem e a própria, e está convencido de que este sacrifício é um absurdo. Com toda a inteligência desejável, compreende que, num clima histórico bem condicionado, os Estados fundados sobre a ideia de Nação encarnam o poder econômico e político e, por conseguinte, também o poder militar, e que todo esse sistema conduz inexoravelmente ao aniquilamento universal.

\section{(...)}

Se o cientista contemporâneo encontrar tempo e coragem para julgar a situação e sua responsabilidade, de modo pacífico e objetivo, e se agir em função deste exame, então as perspectivas de uma solução racional e satisfatória para a situação internacional de hoje, excessivamente perigosa, aparecerão profunda e radicalmente transformadas." 
Albert Einstein

\title{
RESUMO
}

Esse estudo apresenta a proposta de uma reconstrução metodológica da obra de Florian W. Znaniecki, intelectual polonês, com a finalidade de evitar a ocorrência de ecletismo metodológico em estudos de sociologia comparada.

Nesse sentido, argumentamos em favor da forte presença dos fundamentos metodológicos propostos por Henri Poincaré na obra de Znaniecki, devendo ser um fato não negligenciável em análises de sua obra.

Palavras-chave: Reconstrução Metodológica; Valores; Indução Analítica; Ações Sociais; Relações Sociais; Papéis Sociais; Sistemas Sociais; Teoria Sociológica; Florian Znaniecki; Henri Poincaré.

\begin{abstract}
This study presents a proposal for methodological reconstruction of the work of Florian W. Znaniecki, Polish scholar, with the purpose of preventing the occurrence of methodological eclecticism in comparative sociological studies.

In this sense, we argued in favor of the strong presence of methodological foundations proposed by Henri Poincaré in the work of Znaniecki, which shouldn't be a negligible fact in future analyses of his work.

Key terms: Methodological Reconstruction; Values; Analytic Induction; Social Actions; Social Relations; Social Roles; Social Systems; Sociological Theory; Florian Znaniecki; Henri Poincaré.
\end{abstract}




\section{SUMÁRIO}

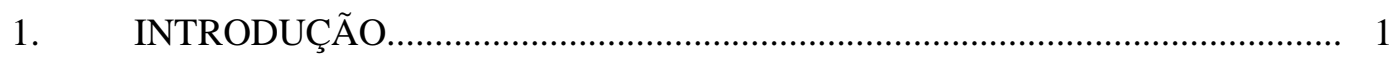

2. A VIDA DE UM HOMEM E O NASCIMENTO DE UM CIENTISTA .......... 2 RESUMO BIOGRÁFICO..................................................................... 4

3. PROPOSTA DE RECONSTRUÇÃO METODOLÓGICA................................ 10 FLORIAN ZNANIECKI E HENRI POINCARÉ........................................... 14 FUNDAMENTOS EPISTEMOLÓGICOS DE POINCARÉ.............................. 16 O CRITÉRIO DE OBJETIVIDADE DA CIÊNCIA.......................................... 17 O FATO BRUTO E O FATO CIENTÍFICO............................................... 18

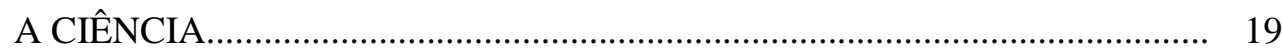
HIPÓTESES, GENERALIZAÇÕES E LEIS............................................. 22 O CARÁTER PROVISÓRIO DAS TOEORIAS............................................... 23

4. A NOTA METODOLÓGICA DE 1918_.................................................... 25 POR UMA CIÊNCIA OBJETIVA........................................................ 29 EM BUSCA DA OBJETIVIDADE DA CIÊNCIA........................................... 37

5. 1934: O MÉTODO DA SOCIOLOGIA.................................................... 42 COEFICIENTE HUMANISTA ............................................................ 43 ATIVIDADE, TENDÊNCIA E ATITUDE........................................................ 44 INDUÇÃO ANALÍTICA...................................................................... 47

6. 1965: O CONCEITO DE PAPEL SOCIAL ..................................................... 51

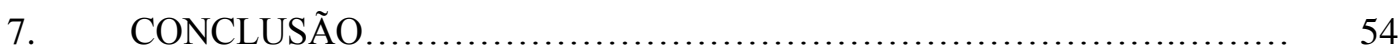

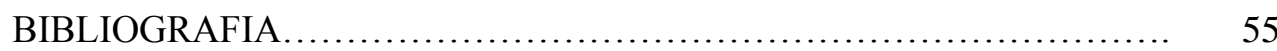




\section{INTRODUÇÃO}

As pesquisas a respeito da produção de Florian W. Znaniecki são abundantes e amplas, tanto quantitativamente quanto tematicamente, principalmente em função de estudos de sociologia comparada que argumentam em favor da viabilidade do estabelecimento de relações entre a obra de Znaniecki e de outros autores, muitos deles clássicos, da sociologia e da filosofia, vinculados a diversas tradições de pesquisa.

Dessa maneira, com o objetivo de contribuir para o esclarecimento conceitual dos estudos a respeito da produção teórica e metodológica de Znaniecki propomos uma reconstrução metodológica, na esperança de que sejam facilitados estudos posteriores a respeito do autor, minorando uma dificuldade explícita em sua obra, fruto da escassez de referências bibliográficas que indiquem as origens do instrumental de fundamentação mobilizado pelo autor. 


\section{A VIDA DE UM HOMEM E O NASCIMENTO DE UM CIENTISTA}

No plano ideal, a partir do momento em que o cientista se percebe vocacionalmente inclinado a dedicar a sua existência à busca pela verdade, naturalmente assume a tarefa de mergulhar nos problemas que se apresentam ainda não resolvidos e compromete-se, por sua vez, consigo e com a humanidade, desejando tornar-se um instrumento para o alargamento das fronteiras do conhecimento humano.

A partir dessa reflexão poderíamos classificar Florian Witold Znaniecki (1882-1958) como um legítimo cientista vocacionado que dedicou sua vida a um projeto de pesquisa cujo objetivo era fornecer uma proposta racional e técnica capaz de equacionar os problemas propostos pela angustiante sucessão de dias vividos por aqueles que foram obrigados a testemunhar duas guerras mundiais.

Segundo Znaniecki, o problema de uma organização ideal da cultura é "o mais amplo e mais antigo problema sociológico, situando-se no limite entre a teoria e a prática", , perspectiva que desenvolveu ao longo de toda sua vida a partir de uma estratégia de busca pelas bases metodológicas e teóricas capazes de oferecer, em um segundo momento, a possibilidade do desenvolvimento de técnicas sociais úteis ao planejamento racional do futuro da humanidade.

Tamanha confiança nas consequências práticas advindas do trabalho teóricometodológico pode vista de forma explícita no último parágrafo de um dos mais aclamados trabalhos da maturidade de Znaniecki, o livro Cultural Sciences:

\footnotetext{
${ }^{1}$ W. I. THOMAS \& F. ZNANIECKI. (2006) "Nota Metodológica", tradução de Mário. A. Eufrasio, Introdução, p. 50.
} 
"Como um sociólogo e filósofo otimista, eu gosto de imaginar que cedo ou tarde a solução para todos os problemas humanos importantes serão confiados aos cientistas culturais, e que os sociólogos assumirão a tarefa de estabelecer como as inovações dos especialistas nas várias esferas da cultura (incluindo a esfera das ciências naturais e suas técnicas) podem ser utilizadas cooperativamente por grupos sociais de agentes práticos para o maior benefício da humanidade. Isso não significa que o futuro da humanidade seria planejado e controlado por sociólogos, assim como Comte imaginou, ou que o mundo humano se tornaria não apenas socialmente unido, mas culturalmente uniforme. Isso significa, na realidade, que os sociólogos funcionariam como líderes intelectuais durante o incessante curso de diferenciação e integração dos papéis sociais e grupos sociais em todo a mundo."2

\section{RESUMO BIOGRÁFICO}

Nascido $^{3}$ próximo a Swiatniki, na Polônia, filho de um administrador de terras, Znaniecki, desde muito cedo, notabilizou-se pela dedicação aos estudos, concluindo o seu Bacharelado em Filosofia na Universidade de Warsaw, na Polônia, e obtendo o título de Mestre em Filosofia na Universidade de Genebra; frequentou cursos em Universidades de Zurique e Paris e conquistou o título de Doutor em Filosofia na Universidade de Cracóvia, em 1909, com uma tese publicada somente polonês com o título O Problema dos Valores na Filosofia (em polonês).

\footnotetext{
${ }^{2}$ ZNANIECKI, Florian. (1952a) Cultural Sciences. Urbana: University of Illinois Press, p 419.

${ }^{3}$ BIERSTEDT, Robert (1969), "Introduction” in ZNANIECKI, F. \& BIERSTEDT, R. (org). Florian Znaniecki: On Humanistic Sociology. Chicago, Chicago University Press. pp 1-34.
} 
Enquanto aguardava por uma oportunidade para lecionar em uma das universidades polonesas, trabalhou como diretor da Associação de Proteção aos Emigrantes Poloneses, fato vital em sua trajetória, pois seria o estopim para que, anos depois, se tornasse uma referência para a sociologia polonesa de importância comparável, por exemplo, à de Florestan Fernandes para a sociologia brasileira.

Na condição de diretor da Associação de Proteção aos Emigrantes Poloneses conheceu e assessorou William Isaac Thomas, sociólogo vinculado à Universidade de Chicago, que desenvolvia uma pesquisa sobre a condição do emigrante polonês em sua terra natal e após a emigração para os Estados Unidos.

O relacionamento intelectual entre Thomas e Znaniecki foi considerável durante esse período, culminando em um convite de Thomas para que Znaniecki fosse trabalhar em Chicago como pesquisador.

Conforme nos diz Dulczewski:

"Em Znaniecki, Thomas encontrou um guia, informante, conselheiro, autêntico estudante de problemas rurais, autor de publicações sobre o tema da migração, (...) um brilhante erudito, filósofo e especialista nas novas tendências da sociologia europeia."

Em julho de 1914, dias antes do início da Primeira Guerra Mundial, Znaniecki viaja para Chicago com a finalidade de aceitar o convite de trabalho junto a Thomas, caracterizando o momento em que silenciosamente a filosofia perdia um dedicado pesquisador e a sociologia ganhava uma profícua e notável mente.

\footnotetext{
${ }^{4}$ DULCZEWSKI, Zygmunt. (1986) "The life history of Florian Znaniecki" in DULCZEWSKI, Zygmunt (org.). A commemorative book in honor of Florian Znaniecki on the centenary of his birth, Póznan: Adam Mickiewicz University, p 18.
} 
Em Chicago, Znaniecki se associou a Thomas no projeto que culminaria, a partir de 1918, com a publicação de cinco volumes com o título The Polish Peasant in Europe and America, trabalho que se tornaria célebre e caracterizado como uma das grandes produções da Universidade de Chicago, passando a ser reconhecido como uma obra clássica na história da metodologia de pesquisa, uma vez que se sustenta sobre um marco metodológico compreensivo, com componentes causais, construído sobre estudos de documentos pessoais (histórias de vida cartas e relatos orais) e estruturado com a finalidade de produzir um diagnóstico sociológico com grande rigor científico, em um contexto em que a pesquisa intuitiva e de senso comum era a principal característica das ciências humanas nos Estados Unidos.

A esse panorama gestacional das ciências humanas no território norteamericano excetua-se o conjunto de trabalhos dos pesquisadores da própria Universidade de Chicago, que, a partir do artigo de 1915, de Robert Park, "The City: Suggestions for the investigation of human behavior in the city environment", desenvolvem um programa de pesquisa claro e de caráter eminentemente científico para a sociologia que, mais tarde, permitiria a caracterização desse grupo como a Escola Sociológica de Chicago. ${ }^{5}$

Znaniecki retornou para seu país de origem em 1920, onde se tornou o primeiro professor de sociologia na Universidade de Poznan e fundou o Instituto Polonês de Sociologia e o periódico Polish Sociological Review.

Nesse período Znaniecki promoveu o primeiro movimento robusto da sociologia como disciplina acadêmica e científica em território polonês, tanto pelo

\footnotetext{
${ }^{5}$ EUFRASIO, Mário (1999). Estrutura Urbana e Ecologia Humana: a escola sociológica de Chicago (1915 - 1940), São Paulo, Editora 34.
} 
impacto de suas ações e publicações [Introdução à Sociologia (1922) e Sociologia da Educação (1928-1930) - ambos permanecem apenas em polonês -, e o livro, em inglês, The Laws of Social Psychology (1925)], quanto pela sua marcante atividade docente.

"Os anos de Znaniecki em Póznan também lhe trouxeram uma exigência de atividade no campo científico-didático. Treinou numerosos grupos de estudantes que, mais tarde desempenhariam, e ainda desempenham, um significativo papel na sociologia em universidades e institutos científicos locais e em outros países. (...)

Durante seus quarenta anos em Poznan, Znaniecki foi orientador de quinze doutores em sociologia e atraiu para o seu entorno um time de discípulos que era conhecido como "Escola Znanieckiana”. Suas aulas eram muito populares e assistidas por numerosos estudantes de outras disciplinas, como filosofia, história, etnografia, filologia polonesa, direito, economia, etc., que eram incluídas nos históricos dos estudantes como temas adicionais. Alguns deles, mais tarde, se "requalificaram" como sociólogos, mudando seus temas principais, ou desenvolveram pós-graduações e doutoramentos em sociologia." ${ }^{6}$

Em 1932 Znaniecki retornou para os Estados Unidos, fixando-se na Universidade de Columbia, localidade na qual permaneceu até 1939 de maneira intermitente, em função de períodos planejados de atividades em Poznan, definindo um contexto criativo caracterizado por uma grande produtividade intelectual, tanto

\footnotetext{
${ }^{6}$ DULCZEWSKI, Zygmunt. (1986) "The life history of Florian Znaniecki" in DULCZEWSKI, Zygmunt (org.). A commemorative book in honor of Florian Znaniecki on the centenary of his birth, Póznan: Adam Mickiewicz University, pp 21-22.
} 
em termos quantitativos, como em qualitativos, publicando obras fundamentais em sua carreira. ${ }^{7}$

Ao final do verão de 1939, a despeito dos rumores de guerra, Znaniecki decide retornar para a Polônia, contudo seu navio foi "interceptado pela Marinha Real e conduzido para um porto britânico. No dia marcado para a chegada do navio em Gdynia $^{8}$ os exércitos nazistas cruzaram a fronteira da Polônia e deram início à Segunda Guerra Mundial. O nome de Znaniecki estava na lista de militantes e professores definidos para serem executados.",

Znaniecki retornou para os Estados Unidos, vinculando-se nesse momento à Universidade de Illinois, enquanto, na Polônia, sua esposa e sua filha passavam pelas dificuldades da Guerra, incluindo um breve período em um campo de concentração na Polônia, de onde conseguiram escapar e emigrar para encontrá-lo em solo americano; sorte que não apresentou o seu filho mais velho, poeta e novelista, que fora preso em Dachau (Alemanha), sendo liberto apenas ao final da Guerra pelas forças Aliadas.

Instalado em Illinois, no início de 1940 conduziu uma pesquisa empírica com estudantes universitários que culminou com o texto The Social Role of the University Student, e em 1952 publicou aquela que, por muitos, é considerada sua obra principal, Cultural Sciences, e, logo em seguida, o volume Modern Nationalities.

\footnotetext{
${ }^{7}$ A saber: Education and Social Change (1930-1933 - Columbia /Pesquisa empírica); The Method of Sociology (1934 - Columbia); Social Actions (1936 - Poznan); The Social Role of the Man of Knowledge (Série de conferências apresentada em Columbia, em 1939, e publicada em 1940).

${ }^{8}$ Cidade portuária polonesa.

${ }^{9}$ BIERSTEDT, Robert (1969), "Introduction” in ZNANIECKI, F. \& BIERSTEDT, R. (org). Florian Znaniecki: On Humanistic Sociology. Chicago, Chicago University Press, pg. 3.
} 
Znaniecki faleceu no Carle Hospital, na cidade de Urbana, Illinois, em vinte e três de março de 1958, em função de arteriosclerose coronariana, deixando incompleto o seu trabalho em torno de uma sociologia geral, o qual foi publicado, ainda que incompleto, em 1965, por sua filha Helena Znaniecka Lopata, com o título Social Relations and Social Roles: The Unfinished Systematic Sociology. 


\section{PROPOSTA DE RECONSTRUÇÃO METODOLÓGICA}

A literatura a respeito das obras de Znaniecki é vasta, diversificada e marcada por inúmeros esforços de análises teóricas e conceituais dentro da própria obra do autor, ou que buscam estabelecer relações com conceitos, hipóteses ou métodos e técnicas de outros autores.

De forma geral, são comuns comentários sobre as influências de Windelband e Rickert sobre Znaniecki, fazendo alusão ao dualismo metodológico adotado pelo autor, identificado pelo uso da divisão entre ciência ideográfica e nomotética, conceitos do neokantismo da Escola de Baden, representada pelos dois autores.

Igualmente comuns são as referências a uma possível influência de Henri Bergson sobre Znaniecki, sustentada por duas razões específicas: a) foi o tradutor de Evolução Criadora, de Bergoson, para o polonês 10; b) Znaniecki adotou o conceito creative ao logo de sua obra, o que poderia ter origem em Bergson.

No livro Cultural Reality, de 1919, o próprio Znaniecki esclarece que se sente influenciado pelo idealismo histórico polonês ${ }^{11}$ e pelo pragmatismo, em relação ao qual se considera um discípulo ${ }^{12}$,uma declaração que foi responsável por justificar diversas referências a respeito, principalmente em relação ao pragmatismo.

\footnotetext{
${ }^{10}$ BERGSON, H. (1913) Evolucja twórcza. Warsaw: Gebethner \& Wolff. (Tradução de Florian Witold Znaniecki)

11 Sobre o idealismo histórico polonês, ver DYCZEWSKI, L. (2002) Values in the Polish Cultural Tradition; Polish Philosophical Studies, III, Washington: The Council for Research in Values and Philosophy (disponível em http://www.crvp.org/book/Series04/IVA-19/contents.htm - acessado em 14/07/2014). Sobre as a ética polonesa, ver JEDYNAK, S. (2005) Polish Axiology: The 20th Century and beyond, Polish Philosophical Studies, V, Washington: The Council for Research in Values and Philosophy (disponível em http://www.crvp.org/book/Series04/IVA-25/contents.htm - acessado em 14/07/2014).

12 "a fonte primária [fazendo alusão às influências da juventude] das visões a partir das quais estou tentando construir uma filosofia da cultura situa-se, portanto, no idealismo histórico polonês. De
} 
Além das referências básicas citadas, há um variado conjunto de estratégias de análise teóricas e metodológicas a respeito do autor, entre as quais podemos $\operatorname{destacar}^{13}$ as aproximações com o interacionismo simbólico (HALAS, 1986; GARY, 2000; BAUMAN, 2000), esforços de explicitação de fundamentação teórica ou metodológica a partir das obras de Charles S. Peirce, William James e de John Dewey (GUNTHER, 1986; BERTILSON, 1986), aproximações com aspectos teóricos presentes em Max Weber (RAINER, 1986; LINHARDT, 1986; RIBICKI, 1986; VAITKUS, 1993; MUCHA，2006), Alfred Schutz (GRATHOFF, 1993; PEREIRA, 2007), Georg Simmel (GUNTHER, 1986; HALAS, 1986), Ludwig Wittgenstein (RAINER, 1986), Karl Popper (MAREK, 1986), Wolfgang Stegmüller (GUNTHER, 1986), ou com aspectos mais amplos da fenomenologia (GRATHOFF, 1994) do pós-modernismo (DONATI, 2000).

Considerando a pluralidade das abordagens desenvolvidas até o presente momento pelos pesquisadores, adotaremos uma estratégia reconstrutivista ${ }^{14} \mathrm{de}$ análise considerando a sua utilidade para a prevenção da patologia metodológica denominada ecletismo, definida pelo "uso de conceitos fora dos seus respectivos esquemas conceituais e sistemas teóricos"

todos os meus débitos recentes, nenhum é maior do que aquele eu devo ao pragmatismo, em relação ao qual, na realidade, estou inclinado a me considerar quase um discípulo." (pp. XIII-XIV)

${ }^{13}$ As diferentes perspectivas de análises a respeito de Znaniecki apresentadas são fruto de uma seleção a partir do material disponível em inglês, podendo ser incrementada e multiplicada conforme for ampliado o número de comentadores abordados.

${ }^{14}$ OLIVEIRA FILHO, José Jeremias de. "Reconstruções metodológicas de processos de investigação social” in Revista de História, São Paulo, n. 107, 1976, p. 263-76.

15 OLIVEIRA FILHO, JOSÉ JEREMIAS DE. "Patologias e regras metodológicas" in Estudos Avançados, vol. 9, n. 23, Janeiro-Abril de 1995, p. 263. 
Segundo Oliveira Filho, a gravidade ecletismo em produções teóricas e metodológicas é apresentada da seguinte forma:

"A ocorrência do termo sem definição que reduzisse ou eliminasse a sua ambiguidade, não permitiria saber a qual de vários conceitos possíveis está associado. Inadvertidamente, muitas vezes, utiliza-se o sinal que expressa o conceito, mas não o próprio conceito. $\mathrm{O}$ discurso torna-se vazio ou obscuro sem que o cientista social perceba que a sua linguagem pode dificultar a comunicação. Se tal ocorrência é grave ao nível da teoria, será gravíssima em nível metateórico ou meta-sociológico. Nesse caso os conceitos metodológicos desprovidos de suas características limitar-se-ão a nomeações e classificações rituais de posturas sem qualquer influência nas estratégias de investigação, o que é comum em textos produzidos por autores desprovidos de treinamento metateórico. Termos vazios de significado não podem funcionar como instrumental de reconstrução teórica ou metateórica."16

Dessa maneira, com o objetivo de contribuir para o esclarecimento conceitual dos estudos a respeito da produção teórica e metodológica de Znaniecki optamos pela estratégia de reconstrução metodológica, definida como um discurso de metateoria hierárquica, decorrente de um processo de investigação que associa o sistema teórico, sistema tecnológico e universo de pesquisa "abordados pela investigação metateórica dotada de recursos lógicos, epistemológicos e ontológicos adequados"17.

\footnotetext{
${ }^{16}$ Ibidem, p. 263.

${ }^{17}$ OLIVEIRA FILHO, José Jeremias de. "Reconstruções metodológicas de processos de investigação social” in Revista de História, São Paulo, n. 107, 1976, p. 269.
} 
Uma vez que a investigação metodológica possui como objeto a linguagem das ciências sociais ${ }^{18}$, é de suma importância que passemos a considerar, como nos aponta Oliveira Filho, que o fazer sociológico implica em decisões no nível dos pressupostos $^{19}$, estabelecendo-se entre os discursos teóricos precedentes presentes e vigentes na comunidade científica, e entre a tecnologia de pesquisa social mobilizada ${ }^{20}$.

Nesse sentido, cada disciplina desenvolve seu próprio universo de disciplina a partir da delimitação de um conjunto de universos de pesquisa, em relação aos quais desenvolve estratégias de métodos e técnicas de pesquisa decorrentes de sistemas teóricos constituídos por conceitos, hipóteses e teorias, sustentados por fundamentos lógicos, epistemológicos e ontológicos, fruto de decisões de manutenção ou de ruptura parcial ou total em relação aos fundamentos, sistemas teóricos ou estratégias de métodos e técnicas em integrantes do instrumental de época disponível. ${ }^{21}$

\footnotetext{
${ }^{18}$ Ibidem. p. 266.

${ }^{19}$ Ibidem. p. 266.

${ }^{20}$ Ibidem. p. 267.

${ }^{21}$ Ibidem. pp. 266 - 276
} 


\section{FLORIAN ZNANIECKI E HENRI POINCARÉ}

A escassez de referências e indicações bibliográficas é uma dificuldade que emerge no estudo da obra de Znaniecki e amplia a possibilidade de compreensão equivocada dos significados dos conceitos utilizados pelo autor.

Apesar de haver um claro esforço de Znaniecki em definir adequadamente os conceitos dos quais se vale, nem sempre esse esforço é suficiente para o pesquisador que pretende desenvolver análises metodológicas específicas, seja para esclarecimentos a respeito dos conceitos, hipóteses e teorias do autor, seja para a composição de análises comparadas, ou ainda com a intenção de utilização dos conceitos do autor em estratégias pluralistas, a partir de combinações teóricoconceituais com outros autores.

Tal contexto se justifica pela dificuldade que surge para o rastreamento das decisões, dos sentidos e dos pressupostos utilizados pelo autor para os conceitos que são apresentados, o que aumenta o risco de incorrermos em ecletismo ao utilizarmos conceitos do autor fora do seu sistema de significado.

Diante desse desafio, após várias tentativas frustradas de estratégias de reconstrução metodológica, deparamo-nos com a hipótese da alta influência de Henri Poincaré na obra de Znaniecki.

A reflexão em torno da possibilidade de utilização da obra de Poincaré como instrumental de reconstrução se deu em função de duas notas de rodapé.

A primeira delas é a nota número 4 , do sexto capítulo de Cultural Sciences, no momento em que Znaniecki se propõe a apresentar, em linhas gerais, a 
“abordagem metodológica que cientistas naturais utilizam para problematizar teorias existentes, atingir novas hipóteses e testá-las. ":

“4) Isso parece presunção de minha parte, uma vez que não sou um cientista natural, fazer alguma exposição geral sobre ciências naturais. Em minha defesa gostaria de pontuar que os princípios metodológicos pelos quais a pesquisa científica é conduzida no domínio da natureza, por um longo tempo têm sido investigados por metodólogos, e as generalizações aqui contidas são originariamente derivadas de seus trabalhos. Atualmente a metodologia científica é um conjunto de produções de cientistas que desenvolveram certos métodos no curso de suas pesquisas, e de filósofos que compararam esses métodos. Alguns famosos filósofos da ciências jamais produziram algum trabalho científico ${ }^{22}$, por exemplo, Francis Bacon; porém, alguns deles também atuaram como cientistas, como Wilhem Wundt. Por outro lado, a maior parte dos cientistas jamais filosofaram sobre métodos, mas alguns sim, como Henri Poincaré. Qualquer conhecimento que eu possa ter sobre métodos das ciências naturais eu devo principalmente, apesar de não exclusivamente, a John Stuart Mill, Ernest and Adrian Naville, Wilhem Wundt, Henri Poincaré, Émile Meyerson, Frederick Barry e Morris Cohen."23

A segunda nota é a de número 2, do quarto capítulo de The Social Role of the Man of Knowledge, no trecho em que o autor discute a questão do problema da descoberta a partir do método da indução:

“2) Há uma vasta literatura sobre os temas discutidos nessa e na próxima sessão; praticamente em sua maioria é, no entanto, a respeito de ciências naturais e cientistas que participaram criativamente de seu desenvolvimento. $\mathrm{O}$ autor ${ }^{24}$ se valeu de tantos

\footnotetext{
${ }^{22}$ Referindo-se a pesquisas empíricas.

${ }^{23}$ ZNANIECKI, Florian.(1952a) Cultural Sciences. Urbana: University of Illinois Press, p. 161.

${ }^{24}$ Znaniecki.
} 
metodólogos, epistemólogos e historiadores que trabalharam nesse campo que haveria a necessidade de um volume para apresentar todos os seus débitos. Ele é maior devedor, provavelmente, de Henri Poincaré, 25

A partir desse ponto decidimos investigar o "tamanho do débito" de Znaniecki em relação a Poincaré, estratégia que nos levou a concluir, como pretendemos demonstrar na presente dissertação, que desde 1918, com sua primeira produção de transição entre a filosofia e a sociologia, a Nota Metodológica, publicada no primeiro volume de The Polish Peasant, até a sua última obra, Social Relations and Social Roles. The unfinished systematic sociology, publicada postumamente em 1965, por sua filha, Znaniecki se vale de elementos de fundamentação oriundos das elaborações propostas por Poincaré.

\section{FUNDAMENTOS EPISTEMOLÓGICOS DE POINCARÉ}

Para a finalidade do presente estudo nos dedicaremos à identificação dos fundamentos epistemológicos presentes na obra de Jules-Henri Poincaré (18541912), a fim de que possamos tornar clara, precisa e objetiva a avaliação da hipótese de mobilização perene desses fundamentos por Florian Znaniecki ao longo de sua obra.

Contudo, para que nossa reconstrução seja adequada devemos levar em conta que, até onde pudemos identificar, Znaniecki mobiliza apenas os elementos

\footnotetext{
${ }^{25}$ ZNANIECKI, Florian.(1940) The Social Role of the Man of Knowledge. New York: Columbia University Press, p. 178.
} 
presentes nas obras A ciência e a hipótese (1902), O valor da ciência (1905) e Ciência e Método (1909), fato indicado por serem os únicos textos de Poincaré citados por Znaniecki ${ }^{26}$, e corroborado por não termos identificado a presença dos temas específicos trabalhados por Poincaré em períodos posteriores.

Dito isso, dedicar-nos-emos a identificar e definir os seguintes elementos em Poincaré: o critério de objetividade da ciência; o fato; a produção do conhecimento científico a partir do fato; a hipótese; o conceito de lei; o caráter provisório das teorias.

\section{O CRITÉRIO DE OBJETIVIDADE DA CIÊNCIA}

Em O Valor da Ciência, a partir de um discurso crítico em relação o nominalismo de Le Roy, Poincaré estabelece que a objetividade não deriva do fato bruto, mas da intersubjetividade entre seres pensantes que estabelecem raciocínios a respeito do mundo das sensações, como podemos observar no trecho que segue:

"O que nos garante a objetividade do mundo no qual vivemos é que esse mundo é comum a nós e a outros seres pensantes. Mediante as comunicações que estabelecemos com os outros homens, recebemos deles raciocínios prontos; sabemos que esses raciocínios não vêm de nós e, ao mesmo tempo, reconhecemos neles a obra de seres racionais como nós. E como esses raciocínios parecem aplicar-se ao mundo de nossas sensações, cremos poder concluir que esses seres racionais viram a mesma coisa que nós; é assim que sabemos que não estávamos sonhando.

\footnotetext{
${ }^{26}$ A única referência bibliográfica sobre Poincaré presente na obra de Znaniecki está contida no livro Métodos da Sociologia, Capítulo 1, item 7: Fatos e Teorias em Sociologia.
} 
Esta é, portanto, a primeira condição da objetividade: o que é objetivo deve ser comum a vários espíritos, e por conseguinte poder ser transmitido de um a outro; e como essa transmissão só se pode fazer mediante o "discurso", que inspira tanta desconfiança ao Sr. Le Roy, somos mesmo forçados a concluir: sem discurso, não há objetividade. ${ }^{, 27}$

\section{O FATO BRUTO E O FATO CIENTÍFICO}

Como uma consequência do critério de objetividade adotado por Poicaré, o autor estabelece a diferenciação entre o fato bruto e o fato científico, como sendo o primeiro a constatação empírica e sensorial de um fenômeno, e o segundo como a elaboração racional que traduz a constatação empírica e a torna intersubjetiva por intermédio da linguagem. ${ }^{28}$

Para Poincaré “o fato científico é apenas o fato bruto traduzido para uma linguagem cômoda" ${ }^{29}$, contudo, diferentemente das consequências que poderiam ser abstraídas da postura nominalista, tal tradução não é fruto de uma invenção por parte do cientista, mas de um raciocínio criterioso e delimitado pelo instrumental teórico e metodológico disponível.

"temos o direito de dizer que o cientista cria o fato científico? Antes de tudo, ele não o cria ex nihilo, já que o faz com

\footnotetext{
${ }^{27}$ POINCARÉ, Henri. O valor da ciência. Rio de Janeiro: Contraponto, 1995, p. 164-165.

${ }^{28}$ VECCHIO JUNIOR, Jacintho Del. A filosofia de Henri Poincaré: a natureza do conhecimento científico e os paradoxos da teoria dos conjuntos. 2005. Dissertação (Mestrado em Filosofia) Faculdade de Filosofia, Letras e Ciências Humanas, Universidade de São Paulo, São Paulo, 2006. Disponível em: <http://www.teses.usp.br/teses/disponiveis/8/8133/tde-07082006-142217/>. Acesso em: 2014-07-27

${ }^{29}$ POINCARÉ, Henri. O valor da ciência. Rio de Janeiro: Contraponto, 1995, p. 147.
} 
o fato bruto. Por conseguinte, não o faz livremente, e como quer. Por mais hábil que seja o trabalhador, sua liberdade é sempre limitada pelas propriedades da matéria-prima sobre a qual opera." ${ }^{, 30}$,

A partir dessa perspectiva emerge a base do convencionalismo moderado de Poincaré, pois para o autor as traduções dos fatos brutos em fatos científicos são viabilizadas a partir de um conjunto de convenções adequadas ao contexto e ao instrumental da época, sendo passíveis de revisões futuras na medida em que a continuidade da pesquisa científica seja capaz de apresentar novas dimensões de relações, com maior capacidade explicativa.

\section{A CIÊNCIA}

Segundo o autor a atividade científica não é capaz de nos fazer conhecer a verdade ou a natureza das coisas, assim como nada o pode, mas ela permite que conheçamos a verdadeira relação entre as coisas.

A contínua atividade de pesquisa, que se justifica por si própria (ciência pela ciência), se dá através de um processo de desvelamento de relações a partir da seleção racional de fatos brutos, com a consequente produção de enunciados científicos, teorias e hipóteses, o que pode culminar com a substituição de hipóteses anteriores, resultando na ampliação da capacidade descritiva do sistema de relações que caracteriza a ciência, cujo ideal máximo seria atingir a compreensão do conjunto de relações que constituem o sistema harmônico do Universo.

\footnotetext{
${ }^{30}$ Ibidem. p. 147.
} 
Nos trechos a seguir o autor nos apresenta algumas definições fundamentais:

Ciência como sistema de relações:

"Então, o que é a ciência? (...) é, antes de tudo, uma classificação, um modo de aproximar fatos que as aparências separavam, embora estivessem ligados por algum parentesco natural e oculto. A ciência, em outros termos, é um sistema de relações." 31

A verdade:

"Portanto, quando nos perguntamos qual é o valor objetivo da ciência, isso não quer dizer "A ciência nos faz conhecer a verdadeira natureza das coisas?". Quer antes dizer "Ela nos faz conhecer as verdadeiras relações entre as coisas?".

À primeira questão ninguém hesitaria em responder não; mas creio que podemos ir mais longe: não só a ciência não pode nos fazer conhecer a natureza das coisas como também nada é capaz de nos fazer conhecê-la, e se algum deus a conhecesse, não poderia encontrar palavras para exprimi-la. Não só não podemos adivinhar a resposta como também, se ela nos fosse dada, não poderíamos entender nada" ${ }^{32}$

\section{A ciência ao longo do tempo:}

“Ora, o que vemos? À primeira vista, parece-nos que as teorias só duram um dia, e que se acumulam ruínas sobre ruínas. (...) Mas há nelas algo que quase sempre sobrevive. Se uma delas nos faz conhecer uma relação verdadeira, essa relação é definitivamente adquirida, e a encontraremos sob um novo disfarce nas outras teorias que virão sucessivamente reinar em seu lugar." 33

\footnotetext{
${ }^{31}$ Ibidem. p, 167.

${ }^{32}$ Ibidem. p, 167.

${ }^{33}$ Ibidem. p, 168.
} 
O ideal da ciência:

“a única realidade objetiva são as relações entre as coisas, de onde resulta a harmonia universal. Sem dúvida essas relações e essa harmonia não poderiam ser concebidas fora de um espírito que as concebe ou que as sente. Porém são objetivas porque são, irão tornar-se ou permanecerão comuns a todos os seres pensantes." 


\section{HIPÓTESES, GENERALIZAÇÕES E LEIS}

O conceito de hipótese utilizado por Poincaré é derivado de seu entendimento da ciência como sendo um sistema de relações, sendo a hipótese constituída pela consolidação, na forma de linguagem comunicável, das relações identificadas pelo cientista.

Para o autor há três tipos de hipóteses:

“Inicialmente, há aquelas que são absolutamente naturais e às quais não podemos fugir. (...) Há uma segunda categoria de hipóteses que qualificarei de indiferentes. (...) As hipóteses da terceira categoria são as verdadeiras generalizações. São aquelas que a experiência deve confirmar ou falsear." ${ }^{34}$

As hipóteses absolutamente naturais, são as relações óbvias, elementares ou que constituem fundo comum a todas as teorias de determinada área.

As hipóteses indiferentes são as relações que não produzem modificação na estrutura da análise desenvolvida pelo cientista.

As generalizações (nome dado ao terceiro tipo de hipótese) são as relações de grande abrangência, com alto teor explicativo, capazes de culminar na produção de leis científicas.

Leis gerais, para o autor, portanto, são relações gerais, ou seja, relações oriundas de pesquisas empreendidas com um conjunto de fatos selecionados racionalmente, cujos resultados permitem a identificar que as relações descobertas são aplicáveis a um amplo conjunto de outros fatos.

${ }^{34}$ POINCARÉ, Henri. A ciência e a hipótese. Brasília: Editora da UNB, 1988, p. 121-122. 
"Descobrir consiste precisamente em não construir combinações inúteis, mas em construir aquelas que são úteis, as quais são uma minoria infinitamente pequena. Descobrir é discernimento; seleção.

(...) Fatos matemáticos merecedores de serem estudados são aqueles que, por sua analogia com outros fatos, são capazes de nos conduzir ao conhecimento de leis matemáticas, da mesma forma que experimentos nos conduzem ao conhecimento de leis físicas. São aqueles que nos revelam relações inesperadas entre outros fatos, há muito tempo conhecidos, mas que erroneamente acreditávamos não se relacionarem entre si." 35

\section{O CARÁTER PROVISÓRIO DAS TOEORIAS}

Em decorrência do instrumental mobilizado, Poincaré nos apresenta um fazer científico que emerge como tradução dos fatos brutos em linguagem científica, permitindo que identifiquemos relações entre os fatos brutos, apresentando-as na forma enunciados e hipóteses, culminando em generalizações que nos levam às teorias e, finalmente, às leis.

Sendo assim, as hipóteses (mais especificamente as generalizações) se dão em função da seleção de fatos feita pelo cientista e estão contextualizadas a partir do conhecimento (teórico e técnico) disponível em sua época, podendo, portanto, ser suplantadas por construções posteriores capazes de confirmar ou modificar as hipóteses vigentes.

Por essa razão, o avanço científico faz com que as teorias sejam substituídas por outras que são compostas por hipóteses que apresentam mais adequadamente o

${ }^{35}$ POINCARÉ, Henri. Science and method. London: Thomas Nelson and Sons, 1914, p. 51. 
sistema de relações entre os fatos, porém, na medida em que determinada relação anterior se mostrou adequada, ela permanece, ainda que a teoria na qual estava originalmente inserida tenha sido substituída.

“À primeira vista, parece-nos que as teorias só duram um dia, e que se acumulam ruínas sobre ruínas. Um dia nascem, no dia seguinte estão na moda, no outro dia se tornam clássicas, no terceiro dia estão obsoletas e no quarto são esquecidas. Mas se prestarmos mais atenção, veremos que o que assim sucumbe são as teorias propriamente ditas, aquelas que pretendem nos ensinar o que são as coisas. Mas há nelas algo que quase sempre sobrevive. Se uma delas nos faz conhecer uma relação verdadeira, essa relação é definitivamente adquirida, e a encontraremos sob um novo disfarce nas outras teorias que virão sucessivamente reinar em seu lugar., ${ }^{36}$

${ }^{36}$ POINCARÉ, Henri. O valor da ciência. Rio de Janeiro: Contraponto, 1995, p. 168. 


\section{A NOTA METODOLÓGICA DE 1918}

A primeira grande contribuição de Znaniecki para a sociologia foi fruto da parceria desenvolvida com William I. Thomas para a produção do The Polish Peasant in Europe and America (1918-20), um papel que é ressaltado pelo fato de pesquisas recentes (GUBERT \& TOMASI, 1993, e HALAS, 2000) indicarem que o célebre primeiro capítulo da obra mencionada, intitulado Nota Metodológica, é de autoria de Znaniecki, com contribuições reflexivas de Thomas, o que o próprio Znaniecki afirma em carta a Kimball Young, e é confirmado por sua esposa Eileen Markley.

"Eu procurei integrar a sua [Thomas] abordagem do fenômeno cultural, enraizado no conceito de atitudes, com minha própria abordagem centrada no conceito de valores, e seu método de investigar indivíduos como participantes da vida social, com o método de investigar coletividades ou "sociedades", assim como foi desenvolvido pela escola de Durkheim (que eu estudei em Paris). Formulei os resultados dessa tentativa (não muito bem sucedida, como vejo agora) na Nota Metodológica, escrita após muitas discussões. ${ }^{, 37}$

"De Junho de 1916 até que o trabalho fosse finalizado, eu trabalhei continuamente no The Polish Peasant, ou seja, até Fevereiro de 1920, quando deixamos os Estados Unidos e fomos para a Polônia. Apesar de ter ajudado a coletar materiais sobre poloneses em Chicago, eu copiei todos os cinco volumes na

\footnotetext{
${ }^{37}$ DULCZEWSKI, Z. "The relevance of the Methodological Note" in HALAS, Elzbieta (ed). Florian Znaniecki's sociological theory and the challenges of 210 century. Berlim: Ed. Peter Lang, 2000, $p$. 227.
} 
máquina de escrever. Eu posso garantir a você que todo manuscrito possuía a letra de Znaniecki, exceto por algumas notas de Thomas e muitas correções de estilo e gramática. Naturalmente, antes de escrever e durante o curso da escrita ele tinha discussões frequentes com Thomas e, como resultado, frequentemente reescrevia partes. Segundo o que me lembro, ele reescreveu A Nota Metodológica três vezes." ${ }^{38}$

Adicionalmente, gostaríamos de destacar não apenas a relevância do fato de a Nota Metodológica ser um texto, em grande medida, da lavra de Znaniecki, como comumente é apresentado por aqueles que a analisam, mas indicamos que o estudo das obras do autor sugerem que a Nota Metodológica pode ser interpretada como um Projeto de Pesquisa que seria desenvolvido e aprimorado por Znaniecki ao longo de sua vida.

Segundo podemos concluir a partir das próprias palavras de Znanicki (ZNANIECKI, 1952B e 1936), o trabalho contínuo sobre os mesmos objetos de investigação era uma de suas características, fazendo-nos crer ser viável um estudo aprofundado dos desenvolvimentos, rupturas e modificações dos esquemas conceituais ao longo da obra do autor, o que pretendemos fazer futuramente.

Por ora, como uma primeira etapa desse trabalho de reconstrução metodológica da obra de Znaniecki, nos manteremos restritos à identificação da influência de Poincaré na obra do autor.

${ }^{38}$ ORBACH, Harold L. "Znaniecki's Contribution to The Polish Peasant" in GUBERT, R. \& TOMASI, L. (eds) The contribution of Florian Znaniecki to sociological theory. Itália: FrancoAngeli, 1993. 
Apenas a título de indicação, podemos adiantar que a Nota Metodológica é composta por cinco grandes temas, que grosso modo poderiam ser identificados como:

1. Argumentação em favor de uma prática científica objetiva.

2. Definição dos critérios para uma prática científica objetiva.

3. Detalhamento sobre a prática científica.

4. Apresentação de uma ciência social nomotética, cujo entendimento proveria as bases para possíveis intervenções sociais.

5. A teoria dos quatro desejos.

Assumindo a Nota Metodológica como um projeto de pesquisa, poderemos encontrar os seus temas distribuídos ao longo da obra do autor da seguinte forma ${ }^{39}$ :

TABELA 1

Partes da Nota Metodológica segundo Temas abordados nas principais obras de Florian Znaniecki

\begin{tabular}{|l|l|c|c|c|}
\hline & $\begin{array}{c}1 \\
\text { Argumentação } \\
\text { em favor de uma } \\
\text { prática científica } \\
\text { objetiva. }\end{array}$ & $\begin{array}{c}2 \\
\text { Definição dos } \\
\text { critérios para } \\
\text { uma prática } \\
\text { científica } \\
\text { objetiva. }\end{array}$ & $\begin{array}{c}3 \\
\text { Detalhamento } \\
\text { sobre a prática } \\
\text { científica. }\end{array}$ & $\begin{array}{c}4 \\
\text { Apresentação de } \\
\text { uma ciência } \\
\text { social } \\
\text { nomotética }\end{array}$ \\
\hline Cultural Reality (1919) & & & & \\
\hline The Laws of Social Psychology (1925) & & & & \\
\hline The Method of Sociology (1934) & & & & \\
\hline Social Actions (1936) & & & & \\
\hline The Social Role of the Man of Knowledge (1940) & & & & \\
\hline Cultural Sciences (1952) & & & & \\
\hline Social Relations and Social Roles (1965) & & & & \\
\hline
\end{tabular}

39 No decorrer de sua produção intelectual a teoria dos quatro desejos foi descartada sem argumentação em contrário 


\section{POR UMA CIÊNCIA OBJETIVA}

Prosseguindo com o objetivo específico da presente dissertação, avançaremos na análise dos elementos da Nota Metodológica sem a pretensão de uma descrição exaustiva do texto, mas com a finalidade de identificar os fundamentos epistemológicos nos permitam avaliar a influência de Poincaré.

A sociologia nos Estados Unidos, assim como na Europa, emergiu em um momento marcado pelo grande desafio do tratamento científico de uma modernidade urbana, acelerada e culturalmente plural.

No caso de Chicago, esse contexto não apenas se apresentava de forma clara, mas também alarmante, pois sua estratégica posição de "posto avançado da civilização americana na frente de expansão do país para o oeste” fez com que, de uma cidade "insignificante em 1840, entre 1850 e 1890 Chicago tornou-se uma grande cidade de mais de um milhão de habitantes - a segunda maior do país - e nos quarenta anos seguintes, cresceu três vezes, atingindo em 1930 quase 3.400 .000 habitantes $", 40$.

A sociologia na Universidade de Chicago surgiu nesse contexto de complexidade e expansão demográfica, institucionalizando-se como disciplina durante o tempo em que as soluções tradicionais para os desafios sociais já se apresentavam inadequadas ou pouco eficientes, ao mesmo tempo em que soluções e práticas capazes de abordar esta nova realidade ainda estavam por serem elaboradas.

${ }^{40}$ EUFRASIO, M. A. Estrutura Urbana e Ecologia Humana: A escola sociológica de Chicago (19151940). São Paulo: Editora 34, 1999, p. 27. 
A disciplina iniciante caracterizou-se em seu primeiro momento pelos traços do melhorismo que se convencionou chamar de "evangelho social", período que foi seguido pela fase dos grandes surveys (apresentando duas fases, a do social survey, caracterizado pelo tipo de pesquisa atrelada ao método dos assistentes sociais, notadamente intuitivo e desprovido de elementos teóricos e analíticos refinados capazes de orientar a coleta de dados, e a do scientific social surveys), quando já havia um esforço de elaboração metodológica, teórica e de métodos e técnicas para subsidiar a pesquisa desde a sua elaboração até a análise final. ${ }^{41}$

A sociologia nos Estados Unidos amadureceu teórica e metodologicamente, na medida em que buscou estabelecer um marco teórico seguro, procedimentos metodológicos, teóricos e de métodos e técnicas capazes de operar um afastamento da sociologia em relação à filosofia social, à ciência baseada no senso comum, às pesquisas elaboradas pelos assistentes sociais e à prática social (intervenção social).

O livro The Polish Peasant in Europe and América, de Thomas e Znaniecki, surge nesse contexto em que a sociologia emergia nos Estados Unidos como uma resposta necessária a uma estrutura social cuja dinâmica interna se apresentava assustadoramente desconhecida.

Em 1918, data da publicação dos dois primeiros volumes desse monumental trabalho (tanto pela importância quanto pela constituição física - 5 volumes, totalizando mais de 2.250 páginas $)^{42}$, apenas há três anos tinha sido publicado "The City: Suggestions for the Investigation of Human Behavior in the City

\footnotetext{
${ }^{41}$ YOUNG, PAULINE. Scientific Social Surveys and Research. 1a ed, New York: Prentice-Hall, 1939.

${ }^{42}$ THOMAS, W. I. \& ZNANIECKI, F. Nota Metodológica. São Paulo, Departamento de Sociologia Faculdade de Filosofia, Letras e Ciências Humanas - Universidade de São Paulo, 2000, p. vii.
} 
Environment" ${ }^{, 43}$, de Robert E. Park , artigo que se sagraria como sendo aquele que estabeleceu o programa de pesquisa que seria aplicado no Departamento de Sociologia da Universidade de Chicago, um fator que, entre outros ${ }^{44}$, contribuiu para a consolidação das condições que tornam o grupo daquele período coeso e coerente, fazendo com que mais tarde fosse considerado como uma "escola", a Escola Sociológica de Chicago. (EUFRASIO, 1999)

Por essa razão, valendo-nos de uma metáfora tupiniquim, podemos notar uma espécie de "bandeirismo" no discurso e na construção dos textos desses autores, apontando a fragilidade da ciência da sociedade com característica intuitiva, filosófica e baseada no senso comum, seguido de um esforço pelo estabelecimento das bases metodológicas de uma sociologia objetiva para, somente em um segundo momento, considerar a possibilidade de intervenções sociais através da aplicação dos resultados científicos alcançados, as quais, por consequência da definição metodológica, deixariam de ser baseados na "boa intenção" e passariam a ser práticas teoricamente orientadas e cientificamente sustentadas, como podemos observar já no primeiro parágrafo da Nota Metodológica. ${ }^{45}$

"Estamos cada vez menos dispostos a deixar qualquer processo social acontecer sem a nossa ativa interferência e nos sentimos cada vez mais insatisfeitos com qualquer interferência ativa baseada no mero capricho de um indivíduo ou de um corpo

${ }^{43}$ PARK, Robert. The City: Suggestions for the Investigation of Human Behavior in the City Environment. The American Journal of Sociology, Vol. 20, No. 5. (Mar., 1915), pp. 577-612

${ }^{44}$ BULMER, Martin. The Chicago School of Sociology: What Made it a School?, The History of Sociology: An International Review, 1985, 5:61-77

${ }^{45}$ Postura que será mantida por Znaniecki ao longo de sua obra e consolidada no livro Modern Nationalities. 
social, ou em generalizações filosóficas, religiosas ou morais preconcebidas." $(\S \mathrm{I} .1)^{46}$

Tamanho ímpeto em instituir o novo, inicialmente se desenvolve como uma argumentação em favor de perspectiva científica que deverá ser objetiva, diferenciando-se, portanto, do subjetivismo filosófico da ciência da sociedade precedente, como vemos a seguir:

"Nosso sucesso em controlar a natureza nos dá a confiança de que deveremos eventualmente ser capazes de controlar o mundo social na mesma medida. Nossa real ineficiência nesse campo se deve não a qualquer limitação fundamental de nossa razão, mas simplesmente ao fato histórico de que a atitude objetiva em relação à realidade social é uma aquisição recente" (§ I.2)

Motivados pela necessidade do estabelecimento de uma postura objetiva para a prática científica, os autores desenvolvem uma argumentação que pretende estabelecer os critérios de objetividade e afastar as práticas pseudocientíficas ou erroneamente tidas como científicas e objetivas.

Inicialmente, Thomas e Znaniecki tratam da crença de que é possível transformar a sociedade por um ato da vontade, praticamente de forma mágica, como se por uma ordem arbitrária fosse consequente e natural a contrapartida social em relação à ação de intervenção na forma de mudança de disposições sociais, forma esta que eles nomearam como ordenar e proibir.

Nessa forma de intervenção social os resultados e as transformações são possíveis, porém, são fruto de processos “mais ou menos acidentais” e dependentes

\footnotetext{
${ }^{46} \mathrm{~A}$ partir desse momento, todas as referências à Nota Metodológica obedecerão à numeração de parágrafos proposta por EUFRÁSIO, 2000.
} 
da "estabilidade das condições gerais" (§I.7), uma vez que as condições gerais de causação não são conhecidas e dominadas.

Por essa razão, há grande ocorrência de efeitos não desejados pois, ao invés de haver uma reflexão a respeito do porquê de um fato, é inserido um "ato da vontade com novos acessórios materiais" (§I.6), caracterizando um método baseado em tentativa e erro, tratando-se, portanto, de uma ação de experimentação social.

Apesar de este período ser considerado como a fase mágica da técnica natural (§I.6) - em oposição à fase científica da técnica social para a qual os autores pretendem contribuir na Nota Metodológica -, é feita uma ressalva em relação à ideia de mágica, pois a ordem ou a proibição podem se tornar efetivas em suas consequências $^{47}$ dependendo da autoridade daquele que a emite.

Como veremos à frente, caso essa ordem seja socialmente validada se transformará em um valor, convertendo-se, por sua vez, em uma regra social, gerando modificação social efetiva.

Em função da ineficácia da técnica do ordenar e proibir, há o desenvolvimento de uma postura científica baseada no senso comum que, igualmente, não se enquadra nos critérios de ciência objetiva almejados.

Segundo os autores, a ciência baseada no senso comum fundamenta-se na "suposição latente de que conhecemos a realidade social porque vivemos nela e que podemos considerar como certas as coisas e relações com base em nossa familiaridade com elas” (§I.10).

\footnotetext{
${ }^{47}$ Teorema de Thomas: "Se as pessoas definem certas situações como reais, elas são reais em suas consequências." em THOMAS, W. I. The child in America: Behavior problems and programs. New York: Knopf, 1928, p. 571-572.
} 
Tal suposição parte do princípio de que o conhecimento adquirido a partir da vivência individual é capaz de abarcar todas as possibilidades de vivência, e que com a decodificação desse código incomensurável da vida estaríamos aptos, como no caso dos anciãos tribais, a sugerir intervenções sociais com alta probabilidade de eficácia.

Portanto, segundo essa concepção, conhecer a realidade seria fruto da experiência adquirida e interpretada subjetivamente, e produziria enunciados que não poderiam ser submetidos à verificação e discutidos pela comunidade científica.

Ademais, a história do desenvolvimento científico demonstra que as concepções baseadas no senso comum correm alto risco de erro, como no caso da relação entre as teorias geocêntrica e heliocêntrica.

Disso decorre uma segunda concepção equivocada de ciência que é aquela baseada nas percepções individuais de um indivíduo ou de um grupo.

Nesse caso, a investigação é orientada por normas, valores e definições daquilo que é normal, anômalo, permissível, desejável ou dignos de conservação, porém, na medida em que uma pesquisa é orientada com este viés, ela perde a possibilidade de encontrar nos fatos corriqueiros e tidos como normais as chaves interpretativas das quais carece, tornando-se, com isso, prescritiva de um certo conjunto de valores que não necessariamente de aplicariam àquela realidade estudada.

Por essa razão os autores defendem que uma pesquisa deve ser iniciada como se o pesquisador nada soubesse ou esperasse dos dados, pois, em sociologia, "uma 
sociologia que use normas como sua base, se priva da possibilidade de compreender e controlar quaisquer fatos importantes da evolução social.” (§I.17)

Um terceiro equívoco em termos de concepção a respeito da prática científica "é a suposição implícita de que qualquer grupo pode ser tratado, teórica e praticamente em um isolamento arbitrário do resto da vida da sociedade dada."

Segundo Thomas e Znaniecki, excetuando-se a fábrica e o exército (casos em que convenções internas aos grupos garantem que nenhum conteúdo externo às normas estabelecidas no interior do grupo será relevante e inspirador de ações, havendo, com isso, um isolamento opcional dos indivíduos), em qualquer outro grupo não há a ocorrência de algum tipo de isolamento que torne o grupo impermeável às influências externas; portanto, é um erro grave a perspectiva de que é possível analisar um determinado grupo social de forma descolada do ambiente que o cerca.

Outro equívoco é a suposição de que todos os indivíduos "reagem da mesma maneira às mesmas influências sem consideração de seu passado individual ou social, e que, portanto, é possível provocar um comportamento idêntico em indivíduos diversos por meios idênticos" (\$I.19), o que torna evidente a inviabilidade de generalizações a partir de uma impressões pessoais.

Como decorrência, uma falha recorrente na ciência prática, é a suposição de que todos os indivíduos reagem com o mesmo proveito, intensidade e consciência a certos estímulos e que, portanto, "é suficiente criar condições favoráveis ou eliminar condições desfavoráveis para dar origem a dadas tendências ou para suprimi-las” (\$I.19). 
Diante desse panorama, emerge a necessidade da definição de critérios claros para construção de uma ciência objetiva e robusta.

\section{EM BUSCA DA OBJETIVIDADE DA CIÊNCIA}

A partir desse ponto da Nota Metodológica os autores desenvolvem enunciados de caráter metateórico, apresentando os fundamentos da ciência da sociedade que pretendem desenvolver.

Primeiramente ressaltamos que os autores, liderados pelas concepções de Znaniecki, alimentam o ideal de que a sociologia atinja o status das ciências naturais, concebida como mais maduras $e$ avançadas, pautando-se em procedimentos científicos definidos com exatidão e rigor.

Tal projeto se realiza, como pretendemos demonstrar, a partir da mobilização dos fundamentos epistemológicos presentes em Poincaré, aplicados ao objeto da sociologia, definido pelos autores.

As evidências nesse sentido são abundantes, iniciando-se com a exposição a respeito do processo de seleção dos materiais, na qual podemos identificar as orientações presentes em Ciência e Método, a partir das quais a descoberta é dependente de discernimento e seleção.

“Tão logo nos tornemos familiarizados com os materiais, começamos a selecioná-los com a ajuda dos critérios que envolvem 
certas generalizações metodológicas e hipóteses científicas. Isso deve ser feito, uma vez que a concretude empírica total não pode ser descrita ou explicada. Temos que nos limitar a certos dados teoricamente importantes, mas devemos saber como distinguir os dados que são importantes.” (§I.29)

Nesse processo de trato científico dos materiais os autores propõem que sejam analisados duas espécies de dados, os valores, que representam os elementos culturais objetivos da vida social, e as atitudes, sendo as características subjetivas dos membros de determinado grupo.

VALOR: "Por valor social entendemos qualquer dado que tenha conteúdo empírico acessível aos membros de algum grupo social e um significado em relação ao qual é ou pode ser um objeto de atividade. (...) O significado desses valores se torna explícito quando os tomamos em conexões com as ações humanas. (...) $\mathrm{O}$ valor social opõe-se, assim, à coisa natural, que tem conteúdo mas, como parte da natureza, não tem nenhum significado para a atividade humana, e é tratado como 'sem valor'; quando a coisa natural assume um significado, ele se torna por esse meio um valor social. E naturalmente, um valor social pode ter muitos significados, pois pode referir-se a muitas espécies diferentes de atividade.”(§I.32)

ATITUDE: "Por atitude entendemos um processo de consciência individual que determina a atividade real ou possível do indivíduo no mundo social. (...) Uma atitude é um processo psicológico tratado como fundamentalmente manifestado em sua referência ao mundo social e tomado em primeiro lugar e em conexão com algum valor social." (§I.33) 
Como podemos observar, o valor é objetivo a ponto de ser caracterizado como um conteúdo empírico acessível, mas é distinto por ser dotado de significado para a atividade humana.

Com isso, o critério de objetividade não é construído a partir da existência bruta, mas pela elaboração humana, em função da atribuição de significado, o que nos remete à argumentação de Poincaré, afirmando que somente é objetivo o elemento comum a todos, inteligível, fruto de raciocínio e elaboração passível de ser comunicada.

Portanto, o que vemos na definição de objetividade do valor, conforme nos parece, é a adaptação do critério de objetividade de Poincaré aos elementos culturais, permitindo que as hipóteses sociológicas estejam assentadas sobre bases objetivas, afastando-se de uma subjetividade que as enfraqueceria em função da peculiaridade humana e viabilizando a busca por relações causais fundamentem generalizações e leis sociais.

“cada passo ulterior da investigação irá trazer consigo novos problemas metodológicos - análise dos dados completos em elementos, sistematização desses elementos, definição dos fatos sociais, leis sociais.” (§I.29)

A esse respeito sugerimos que, na Nota Metodológica, o processo de tratamento do objeto da sociologia é o mesmo sugerido por Poincaré:

$$
\text { fato bruto } \rightarrow \text { fato científico } \rightarrow \text { seleção } \rightarrow \text { busca por relações } \rightarrow \text { generalização } \rightarrow \text { lei }
$$


Uma vez selecionados os valores e as atitudes para análise, a busca por relações explicativas se estabelece como a busca com relações causais (sendo entendidas como relações decorrentes), conforme podemos observar no seguinte trecho:

"Os principais problemas da ciência moderna são problemas de explicação causal. A determinação e a sistematização de dados é somente o primeiro passo na investigação científica. Se uma ciência deseja assentar os fundamentos de uma técnica, precisa tentar compreender e controlar o processo de devir" (§50.II.2)

A busca por relações causais, compostas sempre por uma combinação entre atitude e valor, jamais um ou outro exclusivamente, não seria apenas uma opção ou possibilidade, mas a única forma de obtenção do conhecimento, uma vez que os autores assumem o princípio de que um "fato que não pode ser tratado como uma manifestação de diversas leis é causalmente inexplicável” (\$50.II.13).

$\mathrm{Na}$ medida em que a busca por relações causais explicativas dos dados sociais passa a ser assumida como o objetivo do sociólogo, a etapa decorrente é a identificação de relações causais válidas para contextos sociais além daqueles que foram pesquisados, consolidando-se, com isso, em enunciados com o caráter de generalização, os quais, ao possuírem alto nível de capacidade de generalização, assumiriam o status de lei. 
Os autores são muito enfáticos a esse respeito ao afirmarem que:

"O ideal de teoria social, como de todas as outras ciências nomotéticas, é interpretar tantos fatos quanto possível através de tão poucas leis quanto possível, ou seja, não somente explicar causalmente a vida de sociedades particulares em períodos particulares, mas subordinar essas leis particulares a leis gerais aplicáveis a todas as sociedades de todas as épocas - levando em consideração a evolução histórica da humanidade que continuamente traz novos dados e novos fatos e assim nos força a procurar novas leis em acréscimo àquelas já descobertas" (§ 82.III.13).

Em nossa perspectiva, há fortes razões para assumirmos que o instrumental mobilizado nesse momento para a atribuição de significado aos conceitos de generalização e lei derivam de Poincaré, conforme o que foi exposto no Capítulo 2, o que nos parece mais evidente quando observamos que se para Poincaré o processo de descoberta das relações tende atingir o conjunto de relações que compõem a harmonia universal, Znaniecki (e, talvez, Thomas, ) percorre o mesmo caminho ao afirmar que a descoberta das relações causais produzirão o conhecimento de leis sociais aplicáveis a todas as sociedades de todas as épocas. 


\section{1934: O MÉTODO DA SOCIOLOGIA}

No ano de 1936, na introdução de Social Actions, Znaniecki afirma textualmente que o esquema adotado (atitude-valor-atitude) adotado por ele e por Thomas em The Polish Peasant se demostrou por demais simples.

Uma demonstração dessa perspectiva de amadurecimento conceitual se apresenta particularmente no ano de 1934, quando Znaniecki publica The Method of Sociology, no qual o esquema atividade - tendência - atitude é proposto em substituição ao atitude - valor - atitude (com a modificação do significado de atitude), e são apresentados os conceitos de coeficiente humanista e de indução analítica.

Ao longo deste capítulo pretenderemos demonstrar que os fundamentos epistemológicos oriundos de Poincaré são mantidos em The Method of Sociology, ainda que com algum grau de atenuação.

Retomando as etapas de Poincaré:

$$
\text { fato bruto } \rightarrow \text { fato científico } \rightarrow \text { seleção } \rightarrow \text { busca por relações } \rightarrow \text { generalização } \rightarrow \text { lei }
$$

Observaremos que em The Method of Sociology há a manutenção do critério de objetividade, o conceito de indução analítica se apresenta como um refinamento da ideia de seleção, o esquema atitude - valor - atitude trata da etapa de busca por relações causais, e a generalização e a lei permanecem com ideais a serem atingidos. 


\section{COEFICIENTE HUMANISTA}

No segundo capítulo de The Method of Sociology, intitulado O Princípio de Seleção do Dado Cultural, Znaniecki se dedica a diferenciar o dado natural do dado cultural, sendo o primeiro aquele que é objeto das ciências naturais, que compõem sistemas objetivamente dados aos cientistas e que existem independentemente da experiência e atividade do homem $^{48}$, enquanto que o segundo é composto por um sistema consciente e historicamente ativo ${ }^{49}$.

Znaniecki mantém o valor como o objeto da sociologia, estabelecendo-o como a base dos sistemas culturais, e o define, assim como na Nota Metodológica, como objetivo em função do significado intersubjetivo compartilhado por determinado grupo, mantendo o sentido proposto por Poincaré, conforme vemos a seguir:

"Um valor difere de uma coisa por possuir tanto um dado conteúdo, que o distingue como um objeto empírico de outros objetos, quanto um significado, através do qual ele sugere outros objetos (...) Um valor é tão objetivo quanto uma coisa, uma vez que a experiência de um significado, assim como a experiência de um conteúdo, podem ser repetidas indefinidamente por um número de pessoas e 'testado'.",50

Sendo os valores tão objetivos quanto os dados empíricos, Znaniecki apresenta o termo coeficiente humanista para caracterizar a necessidade de que seja

\footnotetext{
${ }^{48}$ ZNANIECKI, Florian. The Method of Sociology. New York: Farrar and Reinehart, 1934, p. 35.

${ }^{49}$ Idem. p. 36.

${ }^{50}$ Idem. p. 41-42.
} 
incluído nos cálculos das ciências humanas um coeficiente cuja tarefa é garantir que em nenhum momento a análise do dado cultural seja similar à análise de um dado natural, pois tais dados, enquanto objetos dos estudiosos da reflexão teórica, já pertencem à experiência ativa de alguém, e são tais experiências ativas que os constituem $^{51}$.

$(\mathrm{DF} 1+\mathrm{DF} 2+\mathrm{DF} 3)=$ Produto da Ciência Natural

Coeficiente Humanista. $($ DC1 + DC2 + DC3 $)=$ Produto da Ciência Cultural DF = Dado Físico; DC = Dado Cultural

\section{ATIVIDADE, TENDÊNCIA E ATITUDE}

Segundo Znaniecky, o indivíduo, no curso de sua ação desenvolve um percurso que visa a um fim/um objetivo, o qual está associado a um determinado sistema de valores no qual a sua ação possui significado.

Nesse sentido o autor apresenta a definição do conceito de atividade como sendo o conjunto de atos que visam à sua concretização a partir de um sistema de valores específico.

No curso da atividade há dois movimentos que acontecem simultaneamente, o movimento de determinação prospectiva e o de determinação retrospectiva.

${ }^{51}$ Idem. p. 37. 
A determinação prospectiva se refere ao futuro da atividade, sendo pautada em uma ação racional de escolha e combinação dos valores que farão parte das ações e que culminarão no resultado esperado.

A determinação retrospectiva se dá na medida em que o agente empreende ciclos de revisão, modificação em rearranjo dos valores orientadores de sua atividade em função da ocorrência de novos valores ou modificações no sistema de valores no qual a sua atividade está inserida.

Uma tendência, portanto, seria esse movimento da atividade na direção da realização a partir de um sistema de valores.

Com a finalidade de designar a culminação empírica e objetiva da atividade o autor utiliza a expressão construir um sistema de valores [construct a value system].

Isso posto, o autor nos apresenta dois tipos de tendência, primeira que se realiza e culmina empiricamente, e a segunda que permanece latente, denominada atitude e definida pelo autor da seguinte maneira:

"Psicologicamente falando, uma atitude é uma apreciação de um dado objeto como desejável ou não desejável; e essa apreciação pode abranger todo um leque de possibilidades, desde aprovação ou desaprovação puramente intelectuais à mais irracional emoção, ou do sentimento 'estático' ao desejo 'dinâmico'. Em termos objetivos, a atitude é uma determinação do tratamento ativo a um dado valor que seria assumido no sistema que tende a ser construído; se for construído de fato. A atitude é, em outras palavras, o substituto potencial para o ato." 52

${ }^{52}$ Idem. p. 60-61. 
Sendo assim, na medida em que uma atividade se desenvolve a partir de uma tendência significativamente justificada em um dado sistema de valores, Znaniecki reconhece que, ainda assim, ela pode se desenvolver causalmente estável ou não.

A estabilidade causal que sustenta a atividade pautada em uma dada tendência poderia ser comparada a um movimento retilíneo uniforme (variado ou não), no qual um dado corpo em movimento, uma vez mantidas as condições em termos de forças atuantes, tende a permanecer em movimento obedecendo às fórmulas físicas de representação desse tipo de movimento.

Nesse sentido, Znaniecki apresenta o princípio da espontaneidade, a partir do qual "uma tendência cultural é sempre ativa a menos que seja impedida por um obstáculo prático interno. ",53

A singularidade da ação humana e a fluidez da vida, já consideras a partir da determinação retrospectiva, resulta, portanto, no princípio da atingibilidade, segundo o qual "uma vez ativa, uma tendência sempre resulta na construção do sistema de valores para a qual foi iniciada, e nenhum outro, a não ser que seja desviada por fatores perturbadores. "54

Sendo assim, observamos que Znaniecki mantém ativa a concepção de que a ciência se estabelece a partir da busca por ralações, nesse caso causais, explicativas do fenômeno estudado, o que, segundo a nossa análise deriva da concepção de ciência e da atividade científica extraídas de Poincaré.

\footnotetext{
${ }^{53}$ Idem. p. 65.

${ }^{54}$ Idem. pp 68-70.
} 


\section{INDUÇÃO ANALÍTICA}

Desenvolvendo as orientações de seleção de dados colhidas em Poincaré, bem como o processo de produção das hipóteses, generalizações e leis, Znaniecki assume que o trabalho da ciência cultural é produto de uma adequada análise a partir de um conjunto de dados culturais coletados (fatos brutos), selecionados e organizados, a partir dos quais empreendido o processo de análise (fatos científicos), caracterizado pelo desvelamentos das relações que fundamentarão generalizações e leis.

Diante da impossibilidade de dispor da totalidade dos dados culturais possíveis, as ciências culturais necessitam adotar procedimentos indutivos, a partir dos quais, a conclusão extrapola a possibilidade de explicação das premissas, produzindo, portanto, generalizações de caráter probabilista, dotado de sentenças causais que relacionam conjuntos de valores vinculados entre si, formando um sistema cultural; um processo muito semelhante ao que já observamos em Ponicaré.

"Descobrir consiste precisamente em não construir combinações inúteis, mas em construir aquelas que são úteis, as quais são uma minoria infinitamente pequena. Descobrir é discernimento; seleção.

(...) Fatos matemáticos merecedores de serem estudados são aqueles que, por sua analogia com outros fatos, são capazes de nos conduzir ao conhecimento de leis matemáticas, da mesma forma que experimentos nos conduzem ao conhecimento de leis físicas. São aqueles que nos revelam relações inesperadas entre outros fatos, 
há muito tempo conhecidos, mas que erroneamente acreditávamos não se relacionarem entre si." 55

Sendo assim, Znaniecki argumenta que da mesma maneira que a objetividade das ciências culturais obedece às peculiaridades dos objetos culturais, também, o procedimento indutivo também deve ser adequado às características desses objetos; a indução analítica consiste no processo composto pelos critérios seleção dos dados culturais e pela busca por hipóteses (generalizações) a partir dos dados culturais selecionados.

Diferenciando-se da indução enumerativa, caracterizada pela reunião de premissas (coleta de dados), seguida pela identificação de caracteres comuns às premissas, a partir dos quais é produzida uma conclusão de caráter probabilista (indução) que indica uma possível característica verdadeira e justificável para o grupo de premissas comuns reunidas; na indução analítica, é desenvolvido um profundo estudo das premissas possíveis de serem reunidas (análise), seguido pelo processo de reunião das premissas (coleta de dados), que se estabelecerão como a base de um segundo momento, através do qual procurar-se-á identificar o sistema de relações causais que emergem a partir dos dados (indução), produzindo, por fim, hipóteses baseadas em sentenças causais de caráter probabilista, capazes de fundamentar generalizações (extrapolação) e leis.

"Pode-se dizer que a indução analítica termina quando a indução enumerativa se inicia (...) Enquanto ambas formas de indução tendem a atingir verdades gerais e abstratas concernentes a

${ }^{55}$ POINCARÉ, Henri. Science and method. London: Thomas Nelson and Sons, 1914, p. 51. 
dados concretos particulares, a indução enumerativa abstrai por generalizar, enquanto que a indução analítica generalizar por abstrair. A primeira busca em muitos casos por caracteres similares e os abstrai conceitualmente por sua generalidade, presumindo que devem ser essenciais para cada caso particular. A última abstrai, a partir dos casos concretos, caracteres que são essenciais para estes e os generaliza, presumindo que são, até o momento, essenciais, e devem ser similares em muitos casos."

Com clara relação com o sentido do conceito de generalização proposto por Poincaré, a partir do qual, as leis derivam como generalizações de alto poder explicativo, em The Method of Sociology Znaniecki propõe que a tarefa da sociologia consiste na busca por sentenças causais na forma de leis estáticas, as quais são definidas da seguinte maneira:

"Uma lei estática é uma generalização de fatos de dependência estrutural entre elementos específicos. O esquema das leis estáticas em sociologia é: Se um sistema social pertencente a uma classe $\mathrm{M}$ contém um elemento do tipo $b$ (dependente), esse deve conter um elemento do tipo $a$ (dominante)., ${ }^{, 57}$

Ou seja, se em um sistema cultural há determinado valor dependente, deve, necessariamente, existir o valor do qual ele depende, permitindo, com isso, que seja estabelecida a relação de causalidade capaz de prover o nível de explicação almejado, produzindo, com isso, uma generalização (lei estática) que deve se manter

\footnotetext{
${ }^{56}$ Idem. pp 250-251.

${ }^{57}$ Idem. p 273.
} 
coerente enquanto as condições que geraram a abstração prévia à generalização (indução analítica) permanecerem inalteradas.

Znaniecki nomeia esse tipo de procedimento como análise ontogenética.

Segundo o autor, a história humana demonstra que ao longo do tempo a espécie humana, em função de suas escolhas, experiências, atos de vontade coletivos e individuais, transitou por momentos caracterizados pela modificação dos valores componentes dos sistemas culturais, seja por conta de influências do meio, seja por elementos internos aos sistemas culturais.

Sendo assim, Znaniecki indica que a flexibilização das relações causais promovida pelos princípios da espontaneidade e da atingibilidade, quando não acidentais, garantem à espécie humana a possibilidade de modificar de forma duradoura a estrutura de seus sistemas culturais.

Esse tipo dinâmica, segundo o autor, é nomeada como filogênese social, cujo significado sustenta a estrutura da sociologia aplicada que emergirá da estrutura teórico-metodológica apresentada, culminando com o desdobramento da educação como uma solução para a extinção do conflito entre os indivíduos em escala global, ao apresentar as bases para a promoção da solidariedade. (ZNANIECKI, 1934b e 1952b). 


\section{1965: O CONCEITO DE PAPEL SOCIAL}

Publicado postumamente em 1965, a obra Social Relations and Social Roles: the unfinished systematic sociology, contém um refinamento da busca por hipóteses de caráter geral, aplicáveis a todas as sociedades; o conceito de lei deixa de estar presente, e cede lugar à generalização, cujo sentido se refere a relações causais capazes de sustentar um sistema explicativo coerente.

Nessa obra o conceito de valor permanece com a sua definição de objetividade a partir dos elementos significativos compartilhados; o coeficiente humanista é mantido como um princípio necessário para a adequação da pesquisa em ciências culturais, diferenciando-a das ciências naturais; o conceito de indução analítica é abandonado pelo autor, mas permanecem os critérios de seleção e busca por relações explicativas (em sua acepção mais simples e muito próxima à proposta por Poincaré); os conceitos de sistema de valores, atividade, tendência e atitudes, conforme 1934, são abandonados pelo autor.

O tipo de generalização buscada por Znanieckie em Social Relations and Social Roles é caracterizada pela simplicidade e compreendida com um ideal que deve ser perseguido, uma vez que a provisoriedade das teorias tendem a manter as relações que se demonstrem verdadeiras, substituindo as relações que se apresentarem equivocadas e aumentando a capacidade de generalização das teorias.

"Uma vez que a sociologia é uma ciência generalizadora, o objetivo último dos estudantes de relações sociais é o 
desenvolvimento de uma teoria sistemática geral, aplicável a todas as relações sociais, encontradas em todos os tempos e lugares." ${ }^{.58}$

Para Znaniecki, uma teoria sistemática geral é dependente de uma teoria geral dos papéis sociais, caracterizada da seguinte forma:

"Nosso propósito final é desenvolver uma teoria geral dos papéis sociais, a qual, obviamente, será composta pelos quatro componentes básicos (...) pessoa, círculo social, deveres e direitos. Todavia, os padrões culturais de cada um desses componentes variam e mudam tanto que deveríamos iniciar pesquisando [surveying] o leque de suas variações, antes de proceder com a investigação de suas conexões com papéis específicos ou tentar atingir generalizações sistemáticas sobre papéis em relação a sistemas sociais. ${ }^{.59}$

Dessa forma, segundo o autor, um sistema social é composto por um conjunto de relações sociais estabelecidas cooperativamente entre pessoas.

Pessoas são todos os indivíduos que participam cooperativamente de determinado conjunto de relações sociais, inseridas dentro de um círculo social no qual as relações são culturalmente orientadas, dotadas de significado e legitimada a partir dos valores compartilhados.

Cada círculo social estabelece certo conjunto deveres, que esperam ser cumpridos pelos seus integrantes, garantindo o equilíbrio do círculo social, assim

\footnotetext{
${ }^{58}$ ZNANIECKI, Florian. Social Relations and Social Roles. The unfinished systematic sociology. San Francisco: Chandler, 1965, p. 95.

${ }^{59}$ Idem. p. 208-209.
} 
como atribui direitos aos seus membros, garantindo-os a partir de regras de sanções positivas ou negativas aplicáveis a cada um dos membros do círculo social.

Os papéis sociais, por fim, são as ações teatralmente empreendidas e culturalmente padronizadas pelos indivíduos que aderem a determinados círculos sociais.

A partir dessa elaboração o autor passa a analisar as diversas características de círculos sociais típicos, buscando a compreensão de sua dinâmica interna, almejando futuramente viabilizar generalizações capazes de sustentar uma teoria geral do sistema social, atingindo, com isso, relações explicativas da sociedade em tal nível de amplitude, que seria comparado ao ideal da atividade científica apresentado por Poincaré, para quem a atividade científica tenderia a atingir a descrição das relações que compõem o sistema nomeado como harmonia universal. 


\section{CONCLUSÃO}

A partir do exposto, acreditamos ter sido capazes de demonstrar que é inegável a mobilização por Florian W. Znaniecki, dos fundamentos presentes na obra de Poincaré, especificamente, em A ciência e a hipótese (1902), O valor da ciência (1905) e Ciência e Método (1909).

Como pudemos observar, apesar da perenidade da presença desses fundamentos ao longo da obra de Znaniecki, houve uma inegável modificação do tratamento dos conceitos e esquemas teóricos, desde a Nota Metodológica até Social Relations and Social Roles, fato que nos coloca diante do desafio de reconstrução dos conteúdos semânticos dos conceitos e das estratégicas de pesquisa apresentadas pelo autor, identificando possíveis relações com as teorias que compunham o seu contexto de época.

Pretendemos empreender tal trabalho em pesquisas futuras, todavia, como profilaxia ao ecletismo metodológico, tanto para as nossas próximas reconstruções metodológicas, quanto para os próximos trabalhos de sociologia comparada empreendidos por outros pesquisadores, alertamos para a necessidade de não serem negligenciados os elementos poincarerianos na obra de Znaniecki. 


\section{BIBLIOGRAFIA}

BERTILSSON, Margareta. On Znaniecki's Methodology: Analitic Induction as Abductive Knowledge. In: DULCZEWSKI, Zygmunt. (org) A commemorative book in honor of Florian Znaniecki on the centenary of his birth. Póznan: Adam Mickiewicz University, 1886. p 37-48.

BAUMAN, Zygmunt. Florian Znaniecki - Our Contemporary. In: Florian Znaniecki's sociological theory and the challenges of $21^{\circ}$ century. Berlin: Ed. Peter Lang, 2000. p 71-80.

DONATI, Pierpaolo. The Challenge of Universalism in a Multicultural Postmodern Society: A Relational Approach. In: Florian Znaniecki's sociological theory and the challenges of $\mathbf{2 1}^{\circ}$ century. Berlin: Ed. Peter Lang, 2000. p 31-48.

DULCZEWSKI, Zygmunt. (org) A commemorative book in honor of Florian Znaniecki on the centenary of his birth. Póznan: Adam Mickiewicz University, 1886. pp 13-27.

DULCZEWSKI, Zygmunt. (org) What are Sociological Problems?. Poznań: Wydawnictwo, 1994.

FINE, Gary Alan. Framing Norms: The Culture of Expectations and Explanations. In: Florian Znaniecki's sociological theory and the challenges of $21^{\circ}$ century. Berlin: Ed. Peter Lang, 2000. p 49-67. 
GRATHOFF, Richard. Some Phenomelogical Motives in Florian Znaniecki's Early Sociology. In: DULCZEWSKI, Zygmunt. (org) What are Sociological Problems?. Poznań: Wydawnictwo, 1994. p 185-198.

GRATHOFF, Richard. Znaniecki's Conceptions of Social and Sociological Theory. In: GUBERT, R. \& TOMASI, L. (eds). The contribution of Florian Znaniecki to sociological theory. Itália: FrancoAngeli, 1993. p 59-69.

GUBERT, R. \& TOMASI, L. (eds). The contribution of Florian Znaniecki to sociological theory. Itália: FrancoAngeli, 1993.

HALAS, Elzbieta (ed). Education and social change. Berlim: Ed. Peter Lang, 1998.

HALAS, Elzbieta. (2010). Towards the World Culture Society: Florian Znaniecki’s Culturalism, Berlin: Ed. Peter Lang, 2010.

HALAS, Elzbieta. Florian Znaniecki - an Unrecognized Forerunner of Symbolic Interactionism. In: DULCZEWSKI, Zygmunt. (org) A commemorative book in honor of Florian Znaniecki on the centenary of his birth. Póznan: Adam Mickiewicz University, 1886. p 75-90.

HALAS, Elzbieta. Social Values as the Object-Matter of Florian Znaniecki's Culturalistic Sociology. In: GUBERT, R. \& TOMASI, L. (eds). The contribution of Florian Znaniecki to sociological theory. Itália: FrancoAngeli, 1993. p 70-86.

LENHARDT, Gero, Theoretical Perspectives of Ethnic Integration. In: DULCZEWSKI, Zygmunt. (org) A commemorative book in honor of Florian 
Znaniecki on the centenary of his birth. Póznan: Adam Mickiewicz University, 1886. p 304-306.

LÜSCHEN, Günther \& TIBBETTS, Paul. Florian Znaniecki's Sociological Methodology. In: DULCZEWSKI, Zygmunt. (org) A commemorative book in honor of Florian Znaniecki on the centenary of his birth. Póznan: Adam Mickiewicz University, 1886. p 173-194.

MUCHA, J. The concept of "social relations" in classic analytical interpretative sociology: Weber and Znaniecki. In: MALINOWSKI, J \& PIETRUSZCZAK, A (eds.), Essays in Logic and Ontology (Pozna'n Studies in the Philosophy of the Sciences and the Humanities, vol. 91), 119-142. Amsterdam/New York, NY: Rodopi,2006.

OLIVEIRA FILHO, José Jeremias de. Patologias e regras metodológicas. Estudos Avançados, vol. 9, n. ${ }^{\text {o } 23, ~ p a ́ g s . ~ 263-268, ~ J a n e i r o-A b r i l ~ d e ~} 1995$.

OLIVEIRA FILHO, José Jeremias de. Reconstruções metodológicas de processos de investigação social. Revista de História, São Paulo, n. 107, p. 263-76, 1976.

PREWO, Rainer. On the Logic of "Action" and "Action System". A Comparison of Florian Znaniecki, Max Weber and The Analitical Philosophy of Action. In: DULCZEWSKI, Zygmunt. (org) A commemorative book in honor of Florian Znaniecki on the centenary of his birth. Póznan: Adam Mickiewicz University, 1886. p 209-234.

RYBICKI, Pawel. Florian Znaniecki’s Concept of Social Action and its Importance in the Development of Social Thought. In: DULCZEWSKI, Zygmunt. (org) A 
commemorative book in honor of Florian Znaniecki on the centenary of his birth. Póznan: Adam Mickiewicz University, 1886. p 307-309.

VAITKUS, Steven. Znaniecki's Cultural Reality as a Sense Foundation to Weber's Theory of Ideal Types. In: GUBERT, R. \& TOMASI, L. (eds). The contribution of Florian Znaniecki to sociological theory. Itália: FrancoAngeli, 1993. p 115-132.

ZIOLKOWSKI, Marek. The Problem of the Objective Order of the System of Knowledge in the Theories of F. Znaniecki and K. Popper. In: DULCZEWSKI, Zygmunt. (org) A commemorative book in honor of Florian Znaniecki on the centenary of his birth. Póznan: Adam Mickiewicz University, 1886. p 281-290.

ZNANIECKI, Florian. Cultural Reality. Chicago: University of Chicago Press, 1919.

ZNANIECKI, Florian. (1944) Las sociedades de cultura nacional y sus relaciones. Jornadas número 24, El Colegio de México, Centro de Estudios Sociales. Tradução de manuscrito inédito por Vicente Herrero.

ZNANIECKI, Florian. Cultural Sciences. University of Illinois Press: Urbana,1952a.

ZNANIECKI, Florian. Modern Nationalities. University of Illinois Press: Urbana, $1952 b$

ZNANIECKI, Florian. Social Actions. New York: Farrar and Reinehart,1936.

ZNANIECKI, Florian. Social Relations and Social Roles. The unfinished systematic sociology. San Francisco: Chandler,1965 
ZNANIECKI, Florian. The Laws of Social Psychology. Chicago: University of Chicago Press, 1925.

ZNANIECKI, Florian. The Method of Sociology. New York: Farrar and Reinehart, 1934a.

ZNANIECKI, Florian. The object-matter of sociology. American Journal of Sociology, local, data (dia, mês, ano). Caderno, seção ou suplemento, página inicial \&ndash final do artigo.Volume 32, 529 - 584, 1927

ZNANIECKI, Florian. The Social Role of the Man of Knowledge. New York: Columbia University Press, 1940.

ZNANIECKI, Florian. The Sociology of the Struggle for Pomerania. Torún: The Baltic Institute, 1934b.

ZNANIECKI, Florian.(1930) “Qual deveria ser a tarefa social da Educação?” In Socjologia wychowania. ,1930.Tradução de Kleber Tandello Pereira e Martyna J. R. Pereira. 